\title{
Empirical Evidence Of The Strategies Of International Investment Of The Major Multinationals
}

Giuseppe Tardivo, (Email: tardivo@econ.unito.it), Universitá di Torino, Italia Rui T. Dias, (Email: dias@econ.unito.it), Universitá di Torino, Italia

\begin{abstract}
Our work debates the problematic of the definition of internationalization strategies by Multinationals. We give some highlights on the main elements that condition such a process. The main perspective is derived from the analysis of the nature of the process of internationalization. We look for empirical evidence of the elements that influence the process of internationalization. We use data from the internationalization indexes from the UNCTAD's world investment reports from 1990 to 2001, to test our models. Foreign markets' sales and firms' dimension are the factors that statistically explain the behaviour of investment in foreign assets.
\end{abstract}

\section{INTRODUCTION}

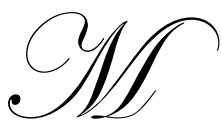

NCs as other firms use in their activity a set of resources such as labour, capital and knowledge. Headquarters' managers have the necessary global perspective to decide over the allocation of those resources. They condition the amount of firms' resources devoted to internationalization strategies accordingly to the proposed objectives. This allocation will structure firms' organization. Affiliates are created with responsibilities over resource management. Control is delegated in these affiliates to manage resources' flows and to supervise the utilization of resources in the productive process.

Our paper focuses on the interdependence of the several internationalization strategies and on the impact that different firm' characteristics such as home-based resources, the amount of foreign market sales, or home employment have on the decision to allocate firms' assets to foreign investment. In section two, we present a theoretical framework on the relationship between firms' process of developing business strategies and the process of internationalization. In section three we look for empirical evidence on internationalization strategies' interdependence and on the relationship between strategies and firm's characteristics. Section four presents our most relevant conclusions.

\section{THEORETICAL FRAMEWORK}

Firms internationalize to benefit from advantages that come from processes such as international scale economies, economies of scope and organizational learning through competition in environmental diversity and in market vicinity. Several models have been developed to explain firms' foreign direct investment [12] and firms' internationalization strategies. The vertical approach model referred to single-plant firm's strategy that fragments the production process into stages, based on international differences in factor prices [6]. In the horizontal model, firms' strategy consists in producing the same product in multiple plants, serving local markets by local production, because trade barriers are considered to be costly. In this case, the production arises as a function of transportation costs and as a function of the product demand [8]. In a third model called knowledge-capital (KC) model it is combined both the vertical and horizontal approaches. Knowledge is created at the headquarters and it is used at affiliates' level. In the "KC" model, FDI is driven by both factor costs and market access opportunities [4]. 
The diversification of such firms (the number of countries and industries in which they are represented), is an important aspect, because this presence has the consequence of increasing the complexity of MNC's systems and their interdependence. In fact, within this system, the manner in which MNCs control their affiliates affects performance [14]. Literature on investment diversification refers that this process allows firms to access investment using crosssubsidisation strategies (by shifting capital within the network of businesses) complementing therefore basic sources of investment such as debt and equity. Furthermore, it is recognized the existence of a set of efficiencies and benefits from the use of flexibilities in capital and labour.

Therefore the change in firms' organization needs to be accompanied by an adjustment of the control system. Control systems are used by top managers to design and implement structural contexts within the firm [1]. In the specific case of geographical dispersion of multinationals, managers use several management tools to devise a remote control system that allows the delegation of key decisions to subunits executives, without putting into danger the firms' overall strategy coherence. Consequently in this case, affiliates are expected to have their strategic objectives aligned accordingly to Headquarters general strategy.

Management tools go from past analysis on terms of performance, resource allocation and budgetary deviations, to structure designing, to authority enforcement (formation of intermediate executives), to planning [3] and to strategy definition and implementation. All these tools need information, data management and measurement systems. In the case of MNCs, the distance between headquarters and affiliates increases the uncertainty regarding the ability to gather reliable operative information.

Control systems are important in the sense that they provide a dual influence on behaviours. The first consequence is that they help solving conflicts in the environment where resources and authority need to be allocated and where decisions need to be made. The second consequence is related to the fact that it is necessary to orientate (coordinate) individual behaviours towards the firms' global strategy giving it the consistency that top management desire. Individual businesses are pressured to develop strategies consistent with group norms [2].

The geographical dispersion is one of the most important characteristics of multinationals. Therefore it is also acceptable that both organisation and coordination of those disperse units assume a vital importance for multinational's strategies implementation. Multinational activity control insures the adherence of affiliates to main goals, minimizing idiosyncratic behaviour and helping to make firm's total performance predictable. Fundamental elements to take into consideration, as far as this mechanism is concerned, are the cost of controlling firms' activity and the necessity (in some cases) to make firms' operative activities flexible to local conditions. Firms achieve coordination by the applications of plans, by the utilization of mutual adjustment mechanisms and by the standardization of instruments. The extent/degree to which a subsidiary is integrated into a MNC depends on the coordination's breadth and diversity.

MNCs' structure integrates a set of multiple activities. MNCs look for country-specific advantages when assessing the alternatives of adjusting the location of those activities in foreign markets. They look for synergies between firm-specific advantages and country-specific advantages [11]. The higher difficulty in reproducing the country-specific advantages, more those country-specific advantages are important to firms. They opt to locate foreign investment in countries that allow them to enhance firm-specific advantages or to offset firm competitive weaknesses.

A MNC, just like any other firm, seeks value creation and long term profitability. In order to accomplish it, it allocates intangible and tangible assets (organizational and technical skills more commonly designated by knowledge [15] [16], production inputs and capital). The existence of a network of intangible and tangible assets is important but it is also important the way it is devised and implemented, because it will have a significant impact on general competitiveness [9]. Headquarters have the necessity to evaluate the efficiency of that allocation throughout the entire network. In such an evaluation, a MNC extends its business analysis to a diversity of environments. It is necessary to get an alignment of internal business strategies to the different conditions from internal and external environments [17]. Firm's growth and value will depend on the capacity to make this alignment [10]. The line of action must comprehend four components: the definition of business strategies, the market penetration decisions, the definition of management structures and the definition of the organizational structures. The dichotomy between centralization and 
decentralization becomes an important choice as far as firm structure is concerned. A firm strategy must include elements of response to threats and opportunities from the environment where firm is located [1]. The firm strategy must take into consideration the relationship between Headquarters and Affiliates and the impact of environmental uncertainty on this relationship.

Affiliates are important elements of the structure because they are the mean MNCs use to supply the market with the firm's product (they organize the necessary elements to produce it: business philosophy, firms' values, they contribute to product conception, they develop local production capabilities, and local distribution networks). As far as the different structural elements of Headquarters-Subsidiaries relationship strategies are concerned, it is believed that centralisation formalisation and normative integration analysed singly and together constitute a comprehensive characterisation of those relationships. From these coordinates it was derived the firm behaviour paradigm expressed in figure $1[5]$.

\begin{tabular}{|l|l|l|}
\cline { 2 - 3 } \multicolumn{1}{c|}{} & \multicolumn{2}{c|}{ Figure 1. Headquarters And Subsidiaries Relationships } \\
\cline { 2 - 3 } $\begin{array}{l}\text { Environmental } \\
\text { Complexity }\end{array}$ & $\begin{array}{l}\text { High Interdependence \& } \\
\text { Subsidiary Dependence }\end{array}$ & $\begin{array}{l}\text { High Interdependence \& } \\
\text { Headquarters Dependence }\end{array}$ \\
\cline { 2 - 3 } & $\begin{array}{l}\text { Low Interdependence \& } \\
\text { Subsidiary Dependence }\end{array}$ & $\begin{array}{l}\text { Low Interdependence \& } \\
\text { Subsidiary Dependence }\end{array}$ \\
\hline
\end{tabular}

Local Resources

Managers set their strategies taking into consideration the way firms relate with local resources and with external environment. Affiliates' autonomy is also believed to depend on the number of countries in which MNCs are present, on the MNCs' product diversity, on the relationship between firms and local resources, and on the kind of the presence of the firms with unrelated industries [14]. Decisions like entry and competition modes are also important because they affect MNCs' global strategies on the short-run and on the long-term [10]. Entry decisions must take into consideration the characteristics of the existing production assets and the market available techniques to combine and implement them. MNCs compete by minimizing the cost of their productive processes or by differentiating the supply [3]. Firms may also take aggressive (increasing market share) or defensive (preserving market share) attitudes when implementing those decisions. MNCs define their strategies like any other firm, with the particularity that they face new markets that mean the existence of multiple preferences; they face new products and they face the existence of new competitors. Institutional framework of new markets and the characteristics of new factor markets are both elements to be taken into consideration, when devising the decision of how to compete. In such a global set, a move into a new market has consequences on all the markets. It is also important to consider in the decision process, that actions taken by competitors from other markets will have consequences in the firms' new market.

After this general scenario on MNC's strategies, two important questions come to our mind: (1) "Is there a relationship between the MNCs' characteristics and Internationalization strategy?", and (2) "If exists this relationship, what is the dimension of the coefficients associated to the explanatory variables?", or put in another way, what is the marginal contribute of each variable in explaining the outcome of that strategy? We use variables such as "homebased invested assets" or "home-based employees" as proxies of firms' characteristics. "Home-based sales" is also an important proxy of firms' characteristics because it shows firms' market dynamics. In the following section we look for the responses for our two questions. 


\section{MODEL ESTIMATION}

The used variables in our empirical study comprehended data from 1990 to 2001, (except for 1991) published in the World Investment Report [13] for the respective years. The foreign abbreviations represent the following variables: $\mathrm{Ha}$ - home-based assets, $\mathrm{He}$ - home-based employment, $\mathrm{Hs}$ - home-based sales, $\mathrm{Ta}$ - total assets, $\mathrm{Fa}-$ foreign assets, $\mathrm{Te}$ - total employment, $\mathrm{Fe}-$ foreign employment, $\mathrm{Ts}-$ total sales and $\mathrm{Fs}-$ foreign sales. $\mathrm{Fa} / \mathrm{Ta}-\mathrm{is}$ used as the internationalization index based on asset analysis, Fs/Ts - is used as the internationalization index based on sales analysis and $\mathrm{Fe} / \mathrm{Te}$ is used as the internationalization index based on employment.

\section{Interdependent Relationships}

Our empirical research looks for evidence on the internationalization strategies from the UNCTAD's database of the most internationalized MNCs. We use variables such as the percentage of assets; sales and employment in foreign market considering them the direct result of internationalization strategies. But how do firms used these different kinds of openings to the exterior, from 1990 to 2001? What influence had one strategy of internationalization over others? In the following graph it is defined an interdependent model between the three different internationalization indexes. The objective is to inquire the relationships between the three different measures and to look for structural differences in the diverse strategies. In this case we have used aggregated data from the sample and we used firms from all industries.

Figure 2: Interdependent Relationships

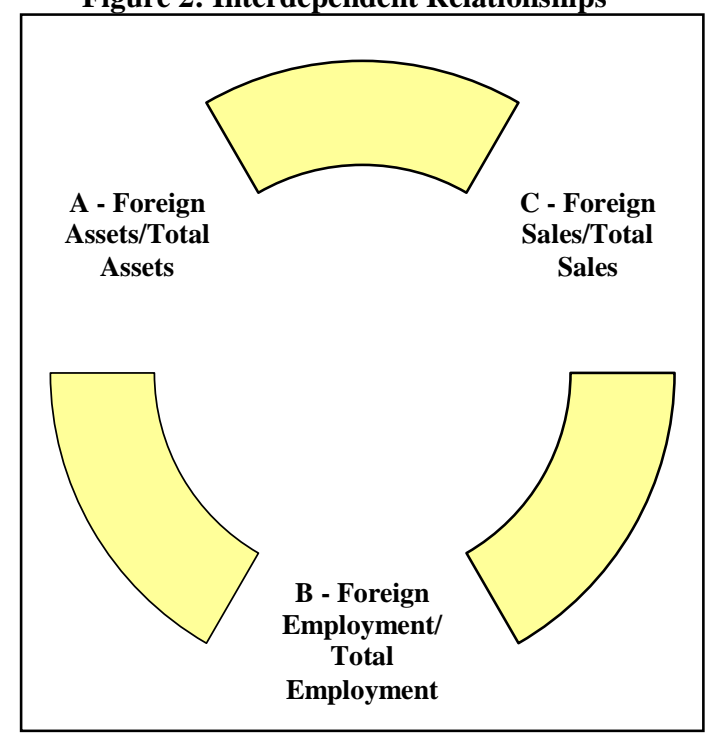

In our estimation through OLS (Ordinary Least Squares), we have estimated each variable against one another and we've obtained the following results: $\partial \mathrm{A} / \partial \mathrm{B}=0.41 ; \partial \mathrm{B} / \partial \mathrm{A}=0.77$ (adjusted $\mathrm{R}^{2}-0.32$ ); $\partial \mathrm{A} / \partial \mathrm{C}=0.67$; $\partial \mathrm{C} / \partial \mathrm{A}=0.53$ (adjusted $\mathrm{R}^{2}-0.53$ ); $\partial \mathrm{C} / \partial \mathrm{B}=0.73$ and $\partial \mathrm{B} / \partial \mathrm{C}=0.49$ (adjusted $\mathrm{R}^{2}-0.35$ ). The smallest partial derivatives where found in the case of the impact of employment index into asset index, in the case of the impact of foreign asset index into foreign sales index and in the impact of foreign sales into foreign employment.

\section{Defining A Linear Model}

We began by analysing the statistics of the variables. We tested the required assumptions for the series to follow a normal distribution. 
Table 1. Variable Statistics

\begin{tabular}{|c|c|c|c|c|c|c|c|c|c|c|c|c|}
\hline & FA & TA & FS & TS & FE & TE & Per_A $^{\mathbf{1}}$ & Per_S & Per_E & HA & HS & HE \\
\hline Skewness & 3.989 & 3.928 & 2.506 & 1.86 & 1.769 & 3.63 & 0.173 & -0.07 & 6.062 & 4.165 & 2.403 & 4.751 \\
\hline Kurtosis & 23.259 & 20.239 & 9.689 & 3.265 & 2.575 & 24.043 & -0.583 & -0.936 & 97.831 & 22.559 & 6.347 & 39.633 \\
\hline
\end{tabular}

From the analysis of the previous table it is possible to see departures from the values that would be assumed in the case series would follow a normal distribution. Skewness measures the asymmetry of the distribution of the series around its mean. Its expected value for a normal distribution is zero. Positive (negative) values mean that the series possesses a long right (left) tail. Kurtosis measures the peakedness or flatness of the distribution of the series. Its expected value for a normal distribution is three. Leptokurtic (Platykurtic) series have this coefficient higher (smaller) than three. Only the variables Per_A and Per_S for Skewness; TS and FE for Kurtosis assume the necessary values of normal distributed series.

We calculated the non-parametric [7] correlation index Spearman rho $\left[\mathbf{S}=\mathbf{1}-\mathbf{6} \sum\left(\mathbf{d}^{2} /\left(\mathbf{n}\left(\mathbf{n}^{2}-\mathbf{1}\right)\right)\right)\right]$ that found statistically relevant values between the log values of foreign assets and all the other variables.

Table 2: Correlation Coefficient

\begin{tabular}{|c|c|c|c|c|c|}
\hline $\log (\mathbf{F A})$ & $\log (\mathbf{H A})$ & $\log (\mathbf{F S})$ & $\log (\mathbf{H S})$ & $\log (\mathbf{H E})$ & $\log (\mathbf{F E})$ \\
\hline Spearman's rho $^{2}$ & 0.38 & 0.75 & 0.36 & 0.22 & 0.52 \\
\hline
\end{tabular}

(all coefficients statistically significant at 99\%)

The Spearman's rank of correlation coefficient is used as a measure of linear relationship between two sets of ranked data. It measures how tightly the ranked data clusters around a straight line. A positive correlation is one in which the ranks of both variables increase together. The most used scale when addressing the Spearman coefficient is the following: values from 0 to 0.5 represent weak positive relation; values from 0.5 to 1 represents strong positive correlation and the exact value of 1 represents perfect positive correlation. Using this criterion and analyzing data from the table it is possible to identify two strong relationships between the logs of the investment in foreign assets and the logs of foreign sales and the log of foreign employment. The effect is stronger in the first case.

Correlation summarizes the strength of the relationship between two variables but it is important to remember that correlation is not causality. So we fitted an exponential regression model in which: $Y_{i}=\beta_{1} X_{i} \beta_{2} \varepsilon$ ei . Algebraic development means that the former expression may be expressed as $\ln Y_{i}=\alpha+\beta_{2} \ln X_{i}+u_{i}$, in which $\alpha=\ln$ $\beta_{1}$. In our model we use the above mentioned variables transformed in logs. The complete expression that represents our model can be defined as:

$\log (\mathrm{FA})=\alpha_{0}+\beta_{2} \log (\mathrm{HA})+\beta_{3} \log (\mathrm{FS})+\beta_{4} \log (\mathrm{HS})+\beta_{5} \log (\mathrm{HE})+\beta_{6} \log (\mathrm{FE})+\varepsilon$

We used OLS estimation method. The obtained coefficients were: $\alpha_{0}=0.593$ (S.E. 0.092); $\beta_{2}=0.16$ (S.E. 0.029 ); $\beta_{3}=0.461$ (S.E. 0.031); $\beta_{4}=7.81$ E-02 (S.E. 0.025); $\beta_{5}=-0.182$ (S.E. 0.027); $\beta_{6}=0.239$ (S.E. 0.026), and adjusted $\mathrm{R}^{2}=0.619$ and Durbin Watson Statistic $=1.504$. All the obtained coefficients were statistically significant at 99\%. We adapted the former model by substituting the dependent variable by Log (FA/TA) (EQ. 3.2.). The obtained results were as following: $\alpha_{0}=3.907$ (S.E. 0.053 ); $\beta_{2}=-0.363$ (S.E. 0.017 ); $\beta_{3}=0.235$ (S.E. 0.018); $\beta_{4}=1.848$ E-02 (S.E. 0.014); $\beta_{5}=-5.17 \mathrm{E}-02$ (S.E. 0.016); $\beta_{6}=9.545 \mathrm{E}-02$ (S.E. 0.015), and adjusted $\mathrm{R}^{2}=0.734$ and Durbin Watson

\footnotetext{
${ }^{1}$ Per_A is the percentage of firm's foreign assets relatively to the value of total assets. Per_A $=($ FA/TA $) * 100$. Per_S is the percentage of foreign sales relatively to firms' total sales and Per_E is the percentage of the number of employees in foreign firms relatively to the total number of employees held globally by the firm.

${ }^{2}$ Spearman Correlation Coefficient - Commonly used nonparametric measure of correlation between two ordinal variables.
} 
Statistic $=1.429$. In this case all coefficients, except $\beta_{4}$, are statistically significant at $99 \%$. In all the cases residuals respect the assumption of normality.

We have decomposed our analysis of the data by Industry. Within our sample we identified the most representative sub-samples and respective number of observations: Beverage (41), Building Materials (9), Chemicals (97), Computers (24), Construction (10), Electronics (139), Food (64), Forestry (6), Metals (34), Motor Vehicles (143), Petroleum Refining (120), Pharmaceuticals (74), Publishing and Printing (13), Retail (15), Telecommunications (53), Trading (46) and Transport and Communication (4). In table number three we show the descriptive statistics of these variables.

Table 3. Industry Statistics

Industry
\begin{tabular}{|l|c|c|c|c|c|c|c|c|}
\hline $\begin{array}{l}\text { Central Tendency And } \\
\text { Dispersion Statistics }\end{array}$ & Mean & Std Dev & Mean & Std Dev & Mean & Std Dev & Mean & Std Dev \\
\hline Food & 4.9 & 9.49 & 0.81 & 14.26 & 14.62 & 86.74 & 4.5 & 15.31 \\
\hline Forestry & 5.86 & 0.92 & 5.44 & 1.51 & 25.01 & 12.84 & 5.23 & 2.22 \\
\hline Metals & 6.76 & 2.27 & 8.51 & 4.88 & 29.82 & 18.49 & 6.26 & 2.67 \\
\hline Construction & 11.68 & 3.48 & 8.52 & 8.51 & 52.59 & 33.73 & 7.99 & 4.19 \\
\hline Trading & 11.789 & 4,67 & 40.76 & 4.67 & 11.94 & 25.37 & 31.18 & 15.13 \\
\hline Building Materials & 12.86 & 5.17 & 11.33 & 8.28 & 53.37 & 14.59 & 7.33 & 2.11 \\
\hline Publishing and Printing & 12.89 & 5.12 & 3.62 & 5.14 & 37.9 & 7.71 & 6.91 & 2.44 \\
\hline Pharmaceuticals & 13.184 & 6.38 & 10.84 & 7.75 & 45.37 & 13.43 & 11.56 & 5.28 \\
\hline Chemicals & 13.42 & 5,92 & 11.6 & 6.54 & 48.24 & 22.87 & 14.07 & 6.06 \\
\hline Transport and & 16.07 & 6.74 & 79.5 & 54.45 & 70.56 & 12.57 & 27.59 & 12.06 \\
\hline Communication & 17.237 & 9.954 & 7.38 & 6.879 & 95.621 & 85.59 & 16.77 & 14.431 \\
\hline Beverages & 17.79 & 7.97 & 17.05 & 16.78 & 168.41 & 92.67 & 23.61 & 9.37 \\
\hline Retail & 20.45 & 22.05 & 28.62 & 44.65 & 65.88 & 59.14 & 21.24 & 18.83 \\
\hline \multicolumn{1}{|c|}{ Total Sample } & 21.9 & 18.44 & 22.01 & 15.93 & 82.02 & 54.43 & 22.91 & 17.16 \\
\hline Computers & 22.79 & 30.8 & 48.83 & 65.74 & 92.91 & 56.14 & 21.1 & 11.51 \\
\hline Electronics & 25.22 & 44.05 & 27.24 & 34.18 & 39.38 & 19.36 & 9.67 & 6.63 \\
\hline Telecommunications & 28.18 & 20.45 & 60.72 & 64.82 & 79.2 & 63.21 & 29.75 & 18.58 \\
\hline Motor Vehicles & 30.96 & 26.19 & 29.05 & 45.72 & 32.4 & 25.96 & 33.84 & 32.8 \\
\hline Petroleum Refining & & & & & & & \\
\hline
\end{tabular}

From the analysis of the previous table (dark-shaded area means total sample mean and leading industries at each indicator) it is possible to see that the sectors that present higher values of foreign assets' mean is Computer (21.9), Electronics (22.79), Telecommunications (25.22), Motor Vehicles and Petroleum Refining (30.96). From these, the Industries with higher value of home-based Assets are Motor Vehicles (60.72) and Electronics (48.83). It seems relevant to point the level attained by Trading (40.76) but mainly Transport and Communication (79.5) that although remaining below the total sample mean takes the leads into this indicator. We estimated EQ. 3.1. with this disaggregated data, only in the case of industries such as Chemicals, Electronics, Motor Vehicles, Petroleum Refining and Pharmaceuticals due to the restriction of the number of observations .

Only in the case of the estimation of the pharmaceutical industry equation if was obtained a statistically significant constant. We also obtained two positive relationships between foreign asset investment log-level and home assets investment log-levels (electronics and petroleum refining). All the coefficients associated with log-levels of foreign assets were found positive and statistically positive. The result in the case of the home based sales was the same but only statistically significant in the estimation of the equations of petroleum and chemicals industries. Home employment log-values presented a negative relationship with the log-value of foreign asset investment. The result 
was inverse (positive) when considering the relationship with log-values of foreign employment. The absolute values of the coefficients allow a comparison between industries. For instance, the effect of home-based assets in investment strategies in foreign assets was found to be greater in electronics than petroleum refining. This industry shows the smallest impact from foreign sales in foreign investment, since they focus their investment not near the final consumer market but mainly near the extracting camps. Motor vehicles and chemical industries have the highest impact from foreign sales into foreign asset investment. They are therefore the industries from our sample that use more marketoriented foreign-asset investment strategies.

Table 4. Industry Sample Estimation Of Equation 3.1.

\begin{tabular}{|l|c|c|c|c|c|c|c|c|}
\hline E.Q.3.1. (log_FA) & Adj R & DW & C & $\log \_$HA & log_FS & $\log \_$HS & log_HE & log_FE \\
\hline Petroleum Refining & 0.87 & 1.78 & 0.0687 & $0.21 * * *$ & $0.31 * * *$ & $0.34 * * *$ & $-0.28 * * *$ & $0.41 * * *$ \\
\hline Motor Vehicles & 0.74 & 1.9 & $(-0.39)$ & $(-0.0349)$ & $0.76 * * *$ & $0.17^{*}$ & $(-7.39 \mathrm{E}-02)$ & $0.17 * * *$ \\
\hline Chemicals & 0.65 & 2.02 & 0.36 & $(-0.0335)$ & $0.81 * * *$ & $0.23 * * *$ & $-0.21 *$ & 0.13 \\
\hline Electronics & 0.78 & 2.44 & 0.523 & $0.706 * * *$ & $0.37 * * *$ & $(-0.09428)$ & $-0.85 * * *$ & $0.54 * * *$ \\
\hline Pharmaceuticals & 0.55 & 1.84 & $1.42 * *$ & $3.45 \mathrm{E}-02$ & $1.11 * * *$ & $1.55 \mathrm{E}-02$ & $-2.16 \mathrm{E}-02$ & $-4.33 \mathrm{E}-01$ \\
\hline
\end{tabular}

* Statistically Significant at $90 \% .{ }^{* *}$ Statistically Significant at $95 \% .{ }^{* * *}$ Statistically Significant at $99 \%$.

Table 5. Industry Sample Estimation Of Equation 3.2.

\begin{tabular}{|c|c|c|c|c|c|c|c|c|}
\hline $\begin{array}{l}\text { E.Q.3.2. } \\
(\log (\text { FA/TA })\end{array}$ & $\operatorname{Adj} R^{2}$ & DW & $\mathbf{C}$ & log_HA & Log_FS & $\log \_H S$ & log_HE & $\log \_F E$ \\
\hline $\begin{array}{l}\text { Petroleum } \\
\text { Refining }\end{array}$ & 0.86 & 1.93 & $-8.57 \mathrm{E} 01 * * *$ & $-0.498 * * *$ & $0.154 * * *$ & $0.253 * * *$ & $(-0.0954)^{* *}$ & $0.21 * * *$ \\
\hline Motor Vehicles & 0.69 & 1.86 & $-0.956 * * *$ & $-5.47 \mathrm{E}-01 * * *$ & $0.468 * * *$ & 0.07309 & $(-0.0446)$ & $0.07986 * *$ \\
\hline Chemicals & 0.81 & 1.7 & $-0.837 * * *$ & $-3.28 \mathrm{E}-01 * * *$ & $0.248 * * *$ & $8.22 \mathrm{E}-02 * * *$ & $(-0.0686)$ & $0.107 * * *$ \\
\hline Electronics & 0.83 & 2.3 & $(-0.465)^{*}$ & $-0.137 * *$ & $0.264 * * *$ & $1.18 \mathrm{E}-01 * *$ & $-0.572 * * *$ & $0.291 * * *$ \\
\hline Pharmaceuticals & 0.82 & 2.2 & $-0.6 * *$ & $-0.392 * * *$ & $0.384 * * *$ & $(-0.00822)$ & 0.03359 & $(-0.0503)$ \\
\hline
\end{tabular}

${ }^{*}$ Statistically Significant at $90 \% .{ }^{* *}$ Statistically Significant at $95 \% .{ }^{* * *}$ Statistically Significant at $99 \%$.

Table 5 differs from the preceding table in the sense that the dependent variable is now the percentage of the firm's investment that it is affected to foreign investment. We find a negative relationship between the relationship of the percentage of the investment affected to foreign markets and the log-value of home-based assets, and a positive relationship with the $\log$-value of foreign sales. In this case the motor vehicles industry maintains its leadership as far as the absolute values of the coefficients are concerned. The results show coherency with the analysis of the precedent table relatively to the negative (positive) relationship between the percentage of foreign investment relatively to firms' total investment and home-based (foreign market based) employment.

\section{CONCLUSIONS}

HA - Firms' Home Assets are used in the model as a proxy of home-based firms' dimension. This variable symbolizes the importance of the home-based dimension in the strategy of foreign markets' assets allocation. FS Foreign Sales is used as a proxy to estimate the importance of foreign markets in the strategy of investing in foreign assets. HS - Home Sales is a proxy used to symbolise the dimension of the share of internal market relatively to the firms' total market. Home number of employees - HE is another variable used to capture the influence of homemarket's firm dimensions, and FE - Foreign number of employees is included in order to capture the effect of labour intensity in asset foreign investment.

From the estimation of the first model the coefficient that obtained higher absolute value was that associated with foreign sales meaning that investing in foreign assets is proportional with the amount of sales in foreign markets. 
In the set of our results, it also assumed relevance the positive relationship between foreign asset investment and home-based firm dimension, but the fact that the second model obtained contradictory signal suggested that results should be analyzed with cautious.

From model 1 estimation results we can conclude that the regression line that best fitted the data was the one that related the index of asset internationalization with that of the sales internationalization index;

- $\quad$ Firms that augment $1 \%$ their international exposure through asset investment are expected to augment $0,77 \%$ their international exposure in terms of employment (this derivative refers to investment strategies in non productive assets or in capital intensive technologies).

- $\quad$ Firms that augment $1 \%$ their international exposure through employment are expected to augment $0,73 \%$ their international exposure in terms of foreign sales (this derivative refers to investment strategies in labourcost saving projects).

- $\quad$ Firms that augment $1 \%$ their international exposure through foreign sales are expected to augment $0,67 \%$ their international exposure in terms of foreign asset investment (refers to internationalization strategies whose objective is to gain access to local markets).

From model 2 estimation, considering Log_FA as dependent variable, we can conclude that: HA showed to be a determinant factor in 2 industries (Petroleum Refining and Electronics). FS showed relevant coefficients in all equations, HS in 3 sectors and HE in three industries. In the three variables (HA, FS, and FE) the sign of the relationship was positive and in the case of FE it was found to be negative. The elasticity labour-capital was found to be higher in industries such as Electronics and Petroleum Refining. From model 2 estimation, considering $\log (\mathrm{FA} / \mathrm{TA})$ as a dependent variable we have confirmed our previous results. The industry with higher coefficient associated with the variable FS was Motor Vehicles and Pharmaceuticals. HS has a positive sign in the case of Petroleum Refining. In this case, firms are from countries with big domestic markets because they are highly industrialized countries, with a great need for energetic resources. Sales in the domestic market allow firms to gather financial resources to invest in extracting heavy machinery. The relationship between the explanative variables and the dependent variable is not homogeneous as far as all sectors are concerned.

We would like to end by suggesting orientation for future research in order to overcome this study's limitations: (1) Models should be re-estimated by using disaggregated data, as far as the country of destiny of foreign direct investment and as far as the typology of assets are concerned; (2) All observations were re-sampled, which made impossible to study how those relationships evolved "per firm" over time. This fact impedes the analysis of the consequence of lagged variables into internationalisation strategies (including the contribute of past expectations); (3) Further research should also find out what's the role of the environmental factors (institutional frameworks) in these strategies; (4) Is there any common factor to firms' characteristics and firms' strategies that can better explain this relationship of causality? (5) Is there a simple causal relationship between firms characteristics and firms strategies or exists a complex mechanism that operates with the contribute of other variables (not expressed in our model?); (6) Sample is biased towards high levels of Internationalisation (It is made up from observation of the world most internationalised firms). The model explains in some measure their strategies. Generalization to cases of firms'market entrance should be taken with caution.

\section{REFERENCES}

1. Birkinshaw, J.M and Morrison, A.J., (1995), Configurations of strategy and structure in subsidiaries of Multinational Corporations, Journal of International Business Studies, 26(4), 729-753

1. Birkinshaw, J.M, Morrison, A.J., and Hulland, J. (1995), Structural and competitive determinants of a global integration strategy, Strategic Management Journal, 16(8), 637-655

2. Brock, D.M. and Barry, D. (2003), What if planning was really strategic? Exploring the strategy-planning relationship in MNCs, International Business Review, 12, 543-561.

3. Carr, D. L., Markusen, J. R., and Maskus, K.E. (2001) Estimating the Knowledge-Capital Model of the Multinational Enterprise. American Economic Review, 91, 693-708. 
4. Ghoshal, S. and Nohria, N. (1989), Internal differentiation within Multinational corporations, Strategic Management Journal, 10 (4), 323-337

5. Helpman, E. (1984), A Simple Theory of Trade with Multinational Corporations, Journal of Political Economy 92, 451-471.

6. Lehmann, E. L. and D'Abrera, H. J. M. Nonparametrics: Statistical Methods Based on Ranks, rev. ed. Englewood Cliffs, NJ: Prentice-Hall, pp. 292, 300, and 323, 1998.

7. Markusen, J. R. (1984), Multinationals, Multi-Plant Economies and the gains from trade, Journal of International Economics, 16, pp. 205-226.

8. Roth, K. and Morrison, A.J., (1992), Implementing global strategy: characteristics of global strategy: characteristics of global subsidiary mandates, Journal of International Business Studies, 23(4), 715-735

9. Rondinelli, D., Rosen, B., and Drori, I. (2001), The struggle for strategic alignment in multinational corporations: managing readjustment during global expansion, European Management Journal, 19(4), 404416.

10. Rugman, A.M. and Verbeke, A., (1992), A note on the transnational solution and the transaction cost theory of multinational strategic management, Journal of International Business Studies, 23(4), 761-771

11. Tardivo, G. and Dias, R. T., (2003), Foreign Investment Models: Empirical evidence from Italy, Journal of Financial Management and Analysis, 16(1), 36-52

12. UNCTAD, (2003), World Investment Report 2003 - Fdi policies for development: national and international perspectives, United Nations, New York and Geneve. (several years)

13. Vachani, S. (1999), Global diversification's effect on multinational subsidiaries' autonomy, International Business Review, 8, 535-560

14. Dias, Rui P., (2005), R\&D and Knowledge: a Theoretical Assessment of the Internationalization Strategies, forthcoming in International Journal of Technology, Policy and Management.Dias, Rui P., (2005), "Internationalization, Knowledge and R\&D: A Literature Review on the strategic behaviour of Innovative Firms", The 2005 European Applied Business Research Conference, Athens.

15. Tardivo, G. and Dias, Rui P., (2004), Internationalisation and the strategic influence of knowledge - the Italian case, International Journal of Business \& Economics. 


\section{NOTES}

